This item was submitted to Loughborough's Research Repository by the author.

Items in Figshare are protected by copyright, with all rights reserved, unless otherwise indicated.

\title{
Effect of graphene-oxide enhancement on large-deflection bending performance of thermoplastic polyurethane elastomer
}

\section{PLEASE CITE THE PUBLISHED VERSION}

http://dx.doi.org/10.1016/j.compositesb.2015.11.033

\section{PUBLISHER}

(C) Elsevier

VERSION

AM (Accepted Manuscript)

\section{PUBLISHER STATEMENT}

This work is made available according to the conditions of the Creative Commons Attribution-NonCommercialNoDerivatives 4.0 International (CC BY-NC-ND 4.0) licence. Full details of this licence are available at: https://creativecommons.org/licenses/by-nc-nd/4.0/

\section{LICENCE}

CC BY-NC-ND 4.0

\section{REPOSITORY RECORD}

Jing, Qifei, Qiang Liu, Lin Li, ZhiLi Dong, and Vadim Silberschmidt. 2019. “Effect of Graphene-oxide Enhancement on Large-deflection Bending Performance of Thermoplastic Polyurethane Elastomer". figshare. https://hdl.handle.net/2134/20071. 


\title{
Effect of graphene-oxide enhancement on large-deflection bending performance of thermoplastic polyurethane elastomer
}

\author{
Qifei Jing ${ }^{\text {a, b, c }}{ }^{\text {, Qiang Liu }}{ }^{\text {a }}$, Lin Li ${ }^{d}$, ZhiLi Dong ${ }^{\text {b, c }}$, Vadim V. Silberschmidt ${ }^{\text {a, * }}$ \\ a Wolfson School of Mechanical and Manufacturing Engineering, Loughborough University, Loughborough, Leicestershire LE11 3TU, UK \\ bInstitute for Sports Research, Nanyang Technological University, 50 Nanyang Avemue, Singapore 639798, Singapore \\ ${ }^{c}$ School of Materials Science and Engineering. Nanyang Technological University, 50 Nanyang Avenue, Singapore 639798, Singapore \\ d School of Mechanical and Aerospace Engineering, Nanyang Technological University, 50 Nanyang Avemue, Singapore 639798, Singapore
}

\begin{abstract}
A B S T R A C T
Thermoplastic polyurethane (PU) elastomers are used as shoe-sole materials due to many excellent properties but their inelastic deformation is a serious deficiency for such applications. Hence, graphene oxide (GO) was introduced into the synthesized thermoplastic PU to produce a GO/PU composite material with enhanced properties. Plastic behaviour of this composite was assessed in cyclic tensile tests, demonstrating reduction of irreversible deformations with the addition of GO. Additionally, in order to evaluate mechanical performance of PU and the GO/PU composite under conditions of large-deflection bending typical for shoe soles, finite-element simulations with Abaqus/Standard were conducted. An elastic-plastic finite-element model was developed to obtain detailed mechanical information for PU and the GO/PU composite. The numerical study demonstrated that the plastic area, final specific plastic dissipation energy and residual height for PU specimens were significantly larger than those for the GO/ PU composite. Besides, the addition of GO into the PU matrix greatly delayed the onset of plastic deformation in PU in a large-deflection bending process. The average residual height and final specific plastic dissipation energy for PU were approximately 5.6 and 17.7 times as large as those for the studied $\mathrm{GO} / \mathrm{PU}$ composite. The finite-element analysis provided quantification of the effect of GO enhancement on the large-deflection bending performance of PU for regimes typical for shoe soles and can be used as a basis for optimization of real composite products.
\end{abstract}

\section{Introduction}

Graphene, a one-atom-thick hexagonal lattice of $\mathrm{sp}^{2}$ carbon atoms, has a two-dimensional sheet-like structure. Due to its many remarkable properties such as high specific surface area, excellent thermal stability, ultrahigh thermal and electrical conductivity, and outstanding mechanical strength [1,2], graphene has attracted tremendous attention from researchers in various areas. Graphene was proven experimentally to be the strongest material ever developed [3]. Widely studied application of graphene was its use as nanofiller in multi-functional polymer composites for drug delivery. infrared-triggered actuators, shape memory devices, molecular electronics, materials shielding electromagnetic interference, and etc. $[4-10]$. As an alternative to graphene, graphene oxide (GO) is also an attractive nanofiller candidate for development of advanced

- Corresponding author. Tel.: +44 (0)1509 227504.

E-mail address: V.Silberschmidtølboro.ac.uk (V.V. Silberschmidt). polymer composite material thanks to its established advantages in the production yield and cost [11]. GO, obtained from the exfoliation of graphite oxide, owns the same framework as graphene and contains numerous oxygen functional groups.

Thermoplastic polyurethane (PU) is an important class of polymers, widely used in various applications such as foams, coatings, elastomers and adhesives. PU has a block copolymer structure, with polyol as soft segment and isocyanate and chain extender as hard segment. The molecular structure of PU could be easily adjusted to fulfil different property requirements [12]. Thermoplastic PU elastomers have been used in many sporting applications such as ski tips, ski boots, fins for surfboards, goggles and inline skates. They have been introduced in athletic footwear since the 1970's, and are mostly used as outsole materials for rugby, American football, golf, soccer shoes, and etc. [13]. Thermoplastic PU elastomers offer a high level of performance as shoe-sole materials in several aspects. With regard to physical properties, they exhibit good lowtemperature performance, great scratch and cut resistance, good 
resistance to seawater and microbial attack, outstanding flex properties and strong abrasion resistance [14,15]. They could also be easily coloured and made into different shapes, which is critica for a footwear industry. In addition, they could be produced with matt and glossy areas moulded together [16]. These materials also show great ability to bond with other materials in a shoe thanks to a reactive nature of the urethane linkage. However, it was widely reported that many thermoplastic PU elastomers were not pure elastic but also exhibiting plasticity [17-19], a deficiency for shoesole materials.

In this study, GO was added into a PU matrix to prepare a GO/PU composite via a solution mixing method. The effect of $\mathrm{GO}$ on plastic properties of PU was investigated experimentally by means of cyclic tensile tests. Apparently, extending analysis of material's behaviour to cases of in-service conditions typical to those of reallife products is very challenging, especially when non-linear factors are considered. This necessitates the use of numerical simulation that has advantages in terms of comprehensive information presented and low costs when compared to parametric experimental studies. Here, in order to study the mechanical performances of PU and GO/PU composite under large-deflection bending typical to shoe soles, the finite-element analysis with Abaqus/Standard was conducted. An elastic-plastic finite element model was developed to obtain detailed mechanical information for PU and the GO/PU composite and quantify the enhancement effect of GO on the largedeflection bending performance of PU. Results of numerical analysis for the in-service behaviour, such as stress concentration and equivalent plastic strain, are useful for the product optimization.

\section{Experimental}

\subsection{Materials}

Graphene oxide (purity $>99 \%$ ) was provided by XFNANO Materials Tech Co., Ltd. (Nanjing, China); it was synthesized from graphite powders using a common Hummers method. Poly caprolactone diol (PCL) (average $\mathrm{Mn} \sim 2000 \mathrm{~g} / \mathrm{mol}$ ), 4,4'-methylenebis(phenyl isocyanate) (MDI) (molecular weight $250.25 \mathrm{~g} / \mathrm{mol}$ ), 1,4-butanediol (BD) (molecular weight $90.12 \mathrm{~g} / \mathrm{mol}$ ) and dibutyltin dilaurate (DBTDL) were all obtained from Sigma-Aldrich. Dimethylformamide (DMF) (Tritech Scientific) was used as received.

\subsection{Preparation of $P U$ and $\mathrm{GO} / \mathrm{PU}$ composite}

In this work, the prepolymerization method [20] was adopted to synthesize thermoplastic PU elastomer. MDI and PCL were used as monomers, with DBTDL and BD employed as the catalyst and chain extender, respectively. The feed molar ratio of MDI: PCL: BD was 6 : 1: 5 , corresponding to a hard-segment content of $49.4 \mathrm{wt} \%$. The solution-mixing method was used to prepare a GO/PU composite. First, $20 \mathrm{mg}$ GO were dispersed in $50 \mathrm{ml}$ DMF to form a colloidal suspension with the aid of an ultrasonication bath. Then $4.98 \mathrm{~g}$ of the synthesized PU were added into the suspension, corresponding to $0.4 \mathrm{wt} \%$ of GO in the GO/PU composite. After PU was completely dissolved with the assistance of magnetic stirring, a homogenizer was used at $9000 \mathrm{r} / \mathrm{min}$ for $15 \mathrm{~min}$, followed by a bath ultrasonication for another $40 \mathrm{~min}$, to ensure homogeneity of the suspension. Finally, a 0.4 wt\% GO/PU composite film was obtained by solution casting. As a control group, the pure PU film was prepared according to the same procedure without any addition of GO.

\subsection{Characterization}

Field Emission Scanning Electron Microscopy (FESEM, JSM 7600F) was used to observe morphological features of GO. Before observation, the powder sample was sputtered with a thin layer of platinum using a sputter coater. Transmission Electron Microscopy (TEM) study was conducted with a Carl Zeiss LIBRA ${ }^{\mathbb{8}} 120$ in-column energy filter TEM system equipped with an integrated OMEGA filter. Leica Ultracut UCT was used to microtome the film sample in order to obtain flakes with a thickness of about $50-100 \mathrm{~nm}$ for TEM observation. Cyclic tensile tests were carried out using an Instron 5569 universal testing machine (Instron, USA). Specimens for tests were prepared based on ISO 527 standard, corresponding to a gauge length of $20 \mathrm{~mm}$. The specimen was loaded to a fixed level of engineering strain of $40 \%$ and then unloaded to a position with a force magnitude of $0.05 \mathrm{~N}$. The loading-unloading cycle was repeated 50 times, with both the loading and unloading processes performed at a crosshead speed of $50 \mathrm{~mm} / \mathrm{min}$, equivalent to a strain rate of $0.042 \mathrm{~s}^{-1}$. All the tests were conducted at room temperature, and three specimens were tested for each material.

\section{Experimental results and discussion}

\subsection{Characterization of GO and GO/PU composite}

The chemical structure of GO and its morphological features are shown in Fig. 1. Obtained from oxidation of graphite, GO contained massive functional oxygen groups. Based on recent studies [21-24], a GO sheet presents $\mathrm{sp}^{3}$-hybridized carbon atoms containing epoxide and hydroxyl groups on the top and bottom surfaces, as well as $\mathrm{sp}^{2}$-hybridized carbon atoms containing carbonyl and carboxyl groups, mostly at the edges. As can be observed from the FESEM image, GO sheets exhibited a wrinkled and folded structure, which was due to the competition between the electrostatic repulsion and van der Waals attraction between $\mathrm{GO}$ sheets $[25,26]$, while their surfaces were fairly smooth.

A TEM image of the obtained GO/PU composite is presented in Fig. 2. As can be clearly seen, GO sheets were dispersed in the PU matrix at a scale of several hundred nanometres; their stacked structure is indicated by a deep colour, in contrast with the surrounding PU matrix. As discussed by Ruoff et al. [23], strong interaction between adjacent Go layers could prevent full exfoliation of GO sheets in organic solvents, e.g. DMF used in this work.
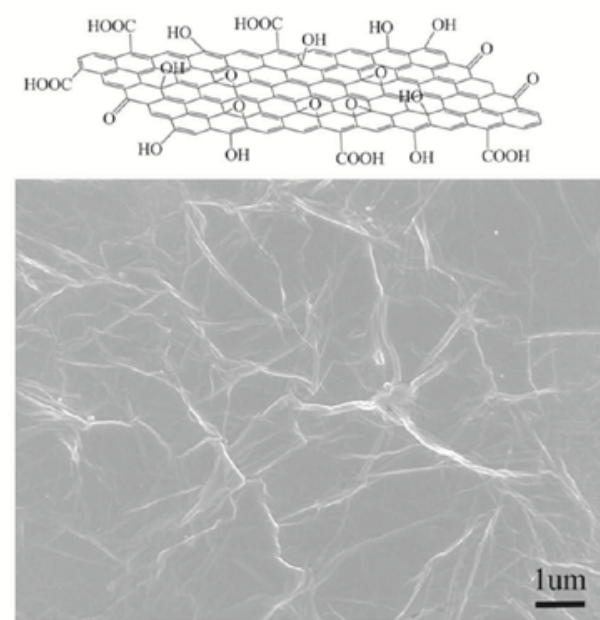

Fig. 1. Chemical structure and FESEM image of GO. 


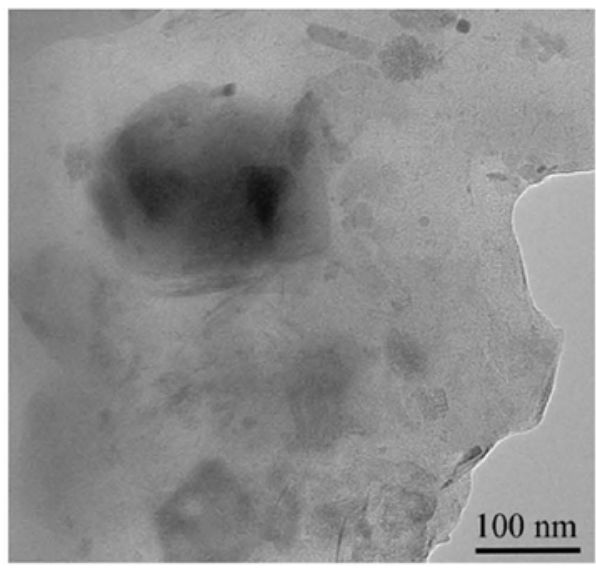

Fig. 2. TEM inage of GO/PU composite.

\subsection{Cyclic tensile tests}

In its service as shoe sole material, the thermoplastic PU elastomer is exposed to various conditions such as repetitive largedeflection bending. So it is important to understand the material's mechanical response to loading-unloading cycles. The data obtained in cyclic tensile tests is presented in Fig. 3, exhibiting typical engineering stress-strain curves for PU and the obtained $\mathrm{GO} / \mathrm{PU}$ composite. It can be clearly seen that PU is not completely elastic within the applied range of engineering tensile strain (40\%). An unrecoverable strain was yielded immediately after the first loading-unloading cycle, which is referred to as plastic strain $\left(\varepsilon_{\mathrm{p}}\right)$ For both materials, the difference between the first and the second loading curves was evident. However, that difference became smaller and smaller for the subsequent loading-unloading cycles, becoming eventually nearly undistinguishable. Compared with PU, the GO/PU composite showed smaller plastic strain after each loading-unloading cycle, indicating a reduced extent of plasticity. The tests on this composite demonstrated a good reproducibility of the obtained results, with a small level of scatter.

The process of accumulation of plastic strain is presented in Fig. 4 providing the values after each cycle (up to 50 cycles) for PU and the GO/PU composite. The plastic strain in PU could be clearly observed; it was attributed to irreversible deformation of its hard segments under external force $[19 \mid$. The lower value of irreversible strain, which served as an indicator of plasticity, for the $\mathrm{GO} / \mathrm{PU}$ composite demonstrated that the addition of $\mathrm{GO}$ into the PU matrix could effectively reduce plasticity of the thermoplastic PU elastomer. A similar effect was often observed in the shapememory property studies of PU-based nanocomposites, where the addition of nanofillers was able to reduce plasticity of PU [27-29]. A widely accepted reason for reduced plasticity was that nanofillers could inhibit the process of irreversible deformation of hard segments due to interactions between them. As for the studied GO/PU composite, the hydrogen bonding between the oxygen functional groups of $\mathrm{GO}$ and urethane linkages of PU could play a significant role in reducing the extent of plasticity of PU |30-32|. Besides, it is apparent that plastic strain for each material experienced a fast increase at the initial few cycles, becoming nearly stable afterwards. Finally, the plastic strain reached $16.1 \%$ and $12.7 \%$ for PU and the GO/PU composite, respectively, after 50 loading-unloading cycles.
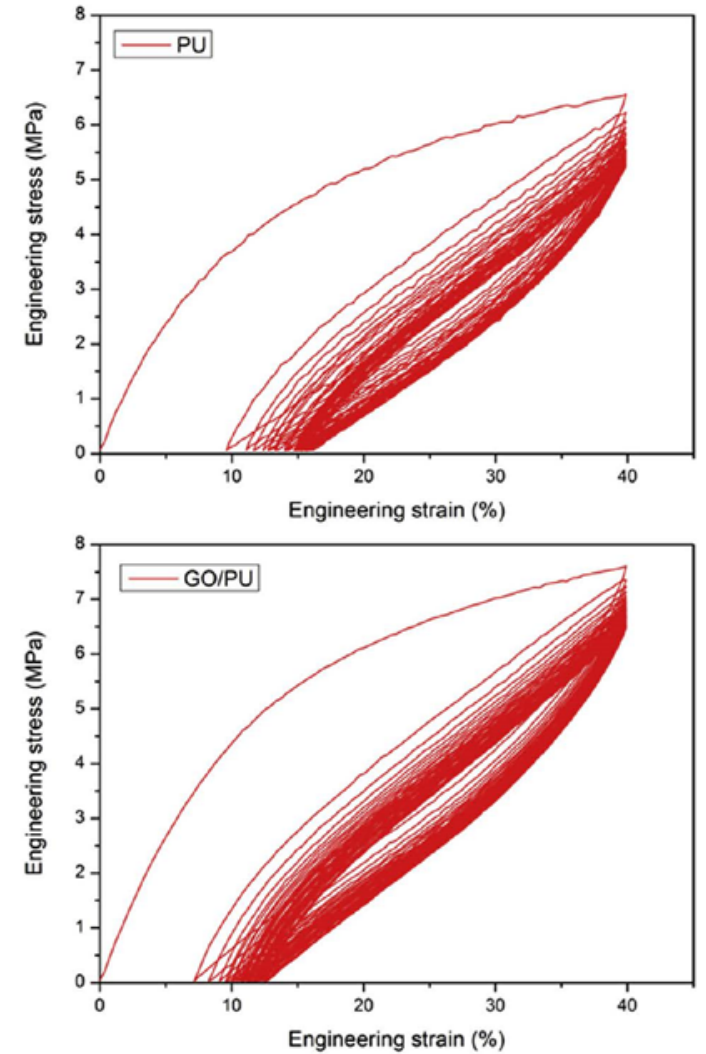

Fig. 3. Typical engineering stress-strain curves of cyclic tensile tests for $P U$ and $\mathrm{GO} / \mathrm{PU}$ composite.

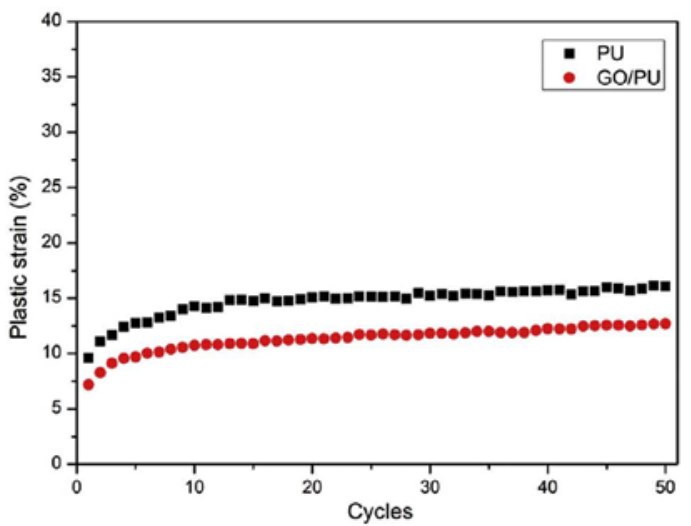

Fig. 4. Plastic strain after each tensile loading-unloading cycle for $P U$ and $G O / P U$ composite.

\section{Finite-element modelling}

For a material exposed to large-deflection bending deformation, as in a case of a shoe sole, the study of relevant mechanical features such as distributions of stresses and plastic deformations as well as 
plastic dissipation energy are fairly complicated due to non-linear mechanical behaviour and non-uniform deformation. The most suitable tool to overcome this is a computational method based on finite-element analysis (FEA) that can obtain comprehensive and detailed information of the studied mechanical behaviour at costs lower than that for detailed experimental analysis. In this study, quasi-static finite-element analysis was performed using commercial FE software Abaqus/Standard to evaluate the largedeflection bending performance of the two materials.

\subsection{Modelling strategy}

An elastic-plastic finite-element model was employed to study the mechanical behaviour of $\mathrm{PU}$ and the $\mathrm{GO} / \mathrm{PU}$ composite material. As shown previously, plastic strain of each material reached a nearly stable state after 50 loading-unloading cycles. In this study, the modelling was developed based on the stabilized level of plastic strain. The first step was to convert the original engineering stress-strain data into the true stress-strain data using the traditional formulae:

$\sigma_{\text {True }}=\sigma_{\text {Eng }}\left(1+\varepsilon_{\text {Eng }}\right)$;

$\varepsilon_{\text {True }}=\ln \left(1+\varepsilon_{\text {Eng }}\right)$,

where $\sigma_{\text {Eng, }} \varepsilon_{\text {Eng, }} \sigma_{\text {True }}$ and $\varepsilon_{\text {True }}$ are the engineering stress and strain, and true stress and strain, respectively.

The value of true plastic strain after 50 loading-unloading cycles $\left(\varepsilon_{\mathrm{p}-50}\right)$ was taken to calculate the elastic modulus for Abaqus input. As the total true strain $\left(\varepsilon_{\text {Total }}\right)$ could be divided into its elastic $\left(\varepsilon_{\mathrm{e}}\right)$ and plastic components $\left(\varepsilon_{p}\right)[33,34]$, as

$\varepsilon_{\text {Total }}=\varepsilon_{\mathrm{e}}+\varepsilon_{\mathrm{p}}$

So the elastic modulus $(E)$ could be obtained from the following relation:

$$
E=\frac{\sigma_{\text {ref }}}{\varepsilon_{\text {ref }}-\varepsilon_{\mathrm{p}-50}}
$$

where $\varepsilon_{\text {ref }}$ is the true strain equivalent to the pre-defined $40 \%$ engineering strain, $\sigma_{\text {ref }}$ is the true stress corresponding to the engineering strain of $40 \%$ in the first loading-unloading cycle. The Poisson's ratio was taken as 0.3 . For input of plastic behaviour into Abaqus, a tabular form for the data on true yield stress and corresponding true plastic strain, calculated with Eq. (3) and the obtained elastic modulus, was used.

\subsection{Geometry and boundary conditions}

A FE model as shown in Fig. 5 was developed to simulate largedeflection bending deformation of a shoe sole, which geometry was simplified as a flat specimen with a length, width and height of $24.0 \mathrm{~cm}, 8.5 \mathrm{~cm}$ and $2.0 \mathrm{~cm}$, respectively; the choice of these dimensions was motivated by a potential application in a sole. Besides, an analytical rigid plane was created to simulate the ground that the shoe sole will contact with. A nominal pressure of $1 \mathrm{MPa}$ was applied at the first quarter of the top surface (AC in Fig. 5) of the sole model to facilitate a contact of the bottom surface with the ground. Other boundary conditions, applied in a local coordinate system, included: (i) constrained translations at Point B; (ii) anticlockwise rotation of surface EF. All translations and rotations of the ground were constrained. A contact between the bottom surface of the material and the ground was defined by node-to-surface

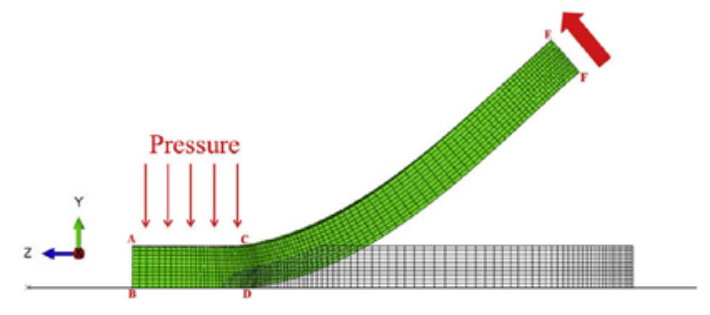

Fig. 5. FE model for simulation of bending of shoe sole.

contact, where the normal behaviour of the interaction was controlled with the 'Hard' contact method.

\subsection{Mesh}

The modelled sole was meshed with 8-noded linear hexahedral elements of type C3D8R, using a structured meshing technique. Prior to performing simulations, the mesh convergence was studied with different mesh densities. The final model, containing a total of 18,900 elements and 22,154 nodes (minimum element length of $0.7 \mathrm{~mm}$ ), was chosen for computationally effective simulations.

\section{Simulation results and discussion}

\subsection{Uniaxial tensile tests}

In order to verify the accuracy of the constructed elastic-plastic model, a quasi-static finite element simulation of uniaxial tensile test was performed using the Abaqus/Standard. The true stress-strain curves of $\mathrm{PU}$ and the GO/PU composite from both experimental studies and finite-element simulation are presented in Fig. 6. As can be seen, the data obtained in FE analysis was highly consistent with those from our experiments, demonstrating that the constructed elastic-plastic model was able to adequately describe the mechanical behaviour of the studied materials, which was the basis for the subsequent simulations.

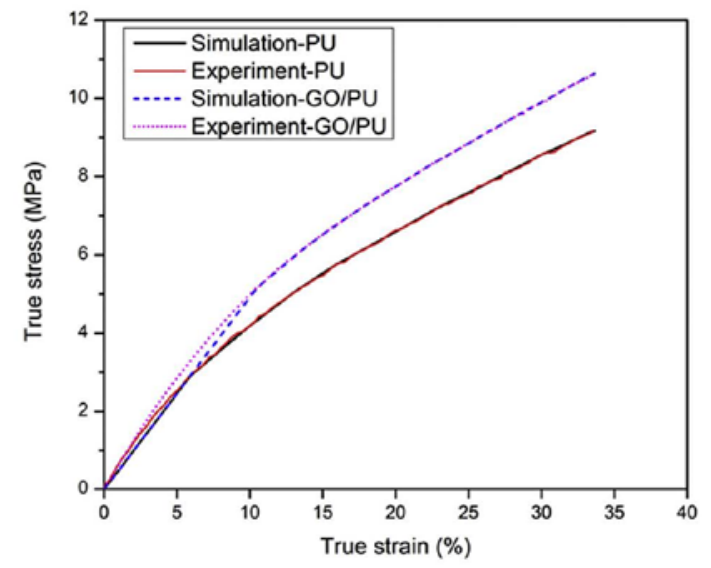

Fig. 6. True stress-strain curves of PU and GO/PU from experiment and simulations. 


\subsection{Stress distribution}

The results of finite-element simulations for distribution of the von Mises stress in the model are presented in Fig. 7 for two viewing angles both for PU and the GO/PU composite for the highest level of deflection. It is obvious that von Mises stress was mostly concentrated in the bending part of the model. The bottom surface of the bending part showed higher stress concentration than the top surface, because it was subjected to larger deformation. Besides, the GO/PU composite exhibited higher levels of von Mises stress compared with those in PU. From inspection, the maximum von Mises stress for PU and the GO/PU composite was found to be $5.36 \mathrm{MPa}$ and $6.05 \mathrm{MPa}$, respectively. The detailed information of von Mises stress distribution obtained from the simulation results can be very useful for product optimization, either by changing the material or adjusting the geometry, when extending analysis to in-service behaviour of real products.

\subsection{Residual height}

After reaching the maximum deformation, the boundary condition applied on surface EF (Fig. 5) was released and the model of sole returned to a position where no further displacement would happen. Due to the onset of plasticity, the initial state could not be reached after unloading in high-deflection bending. In Fig. 8a, the contours of equivalent plastic strain (PEEQ) of the side surface for $\mathrm{PU}$ and the GO/PU composite are presented. Apparently, both models could not return to their original shapes, exhibiting unrecoverable deformations. The distance between the bottom edge $F$ (Fig. 5) and the ground was noted as 'residual height' and recorded along with the simulation time. Obviously, the residual height for PU was more significant than that of the GO/PU composite. Additionally, a larger zone of plastic deformation was observed in PU (as indicated by the PEEQ contour), which was consistent with the results for residual-height difference. The height-time history output for PU and the GO/PU composite is shown in Fig. 8b (time was a mere parameter in this quasi-static study). Both curves exhibited a plateau after unloading (for time of 2.0 ), indicating that the model experienced no further deformation afterwards and proving completion of the 'unbending' process for each material. Meanwhile, a direct quantitative comparison between the residual heights of $\mathrm{PU}$ and the $\mathrm{GO} / \mathrm{PU}$ composite could be observed through the curves (detailed information is included in Table 2).

\subsection{Plastic zone}

A separate study focussed on the size of plastic zone: Fig. 9 shows the contour of equivalent plastic strain (PEEQ) of the top and bottom surfaces for pure PU and the GO/PU composite. It is obvious that PU has much larger plastic areas for all the three surfaces - side surface (Fig. 8a-A), top surface (Fig. 9-C) and bottom surface (Fig. 9-D)

In order to quantitatively describe the difference of plastic areas for the two studied materials, the areas with plastic deformation (i.e. colours of PEEQ contours) were measured with the software Photoshop and expressed as numbers of pixels, as shown in Table 1. Obviously, the initial total areas of the three surfaces were the same for both materials. After the loading-unloading process of the model in the simulation, the total area and plastic areas were measured for all three surfaces. Then, the fraction of plastic area after unloading was obtained by dividing the plastic area with the respective total area (due to irreversible deformation the latter differed from the initial total area). The respective fractions for the side, top and bottom surfaces for PU were 12.6,21.3 and 4.7 times as large as those for the GO/PU composite.

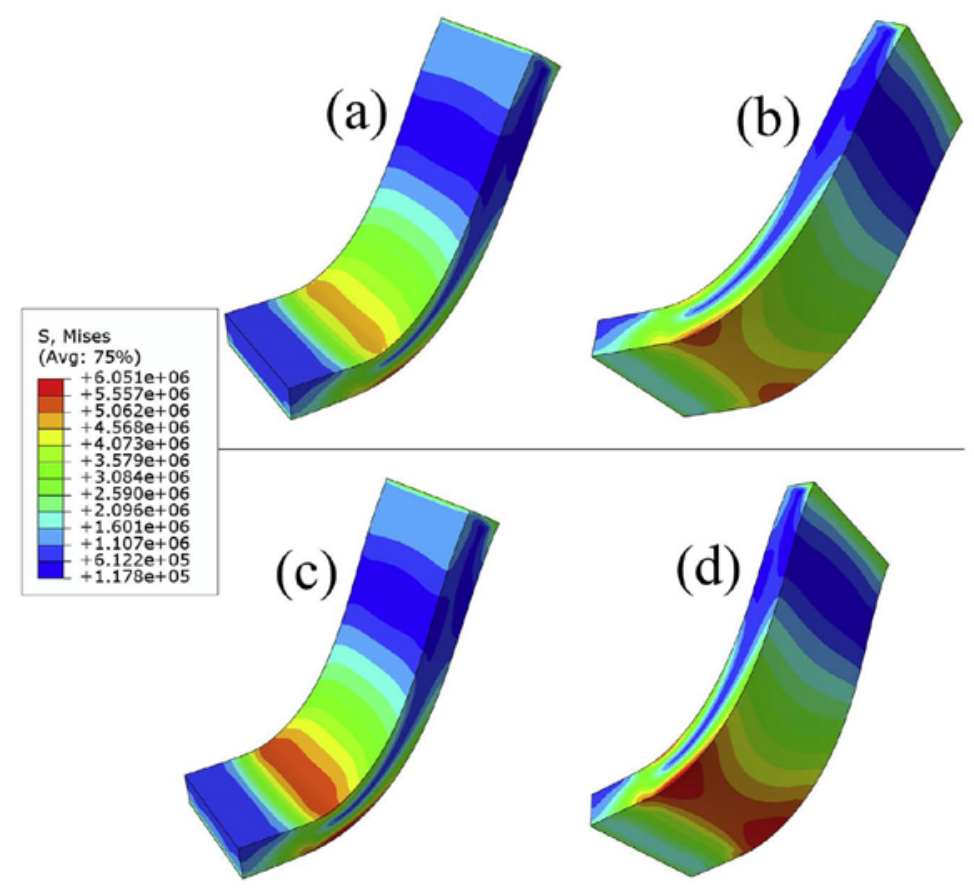

Fig. 7. Contour of von Mises stress (in Pa) distribution for two viewing angles for PU (a, b) and GO/PU composite (c, d) at highest level of deflection. 

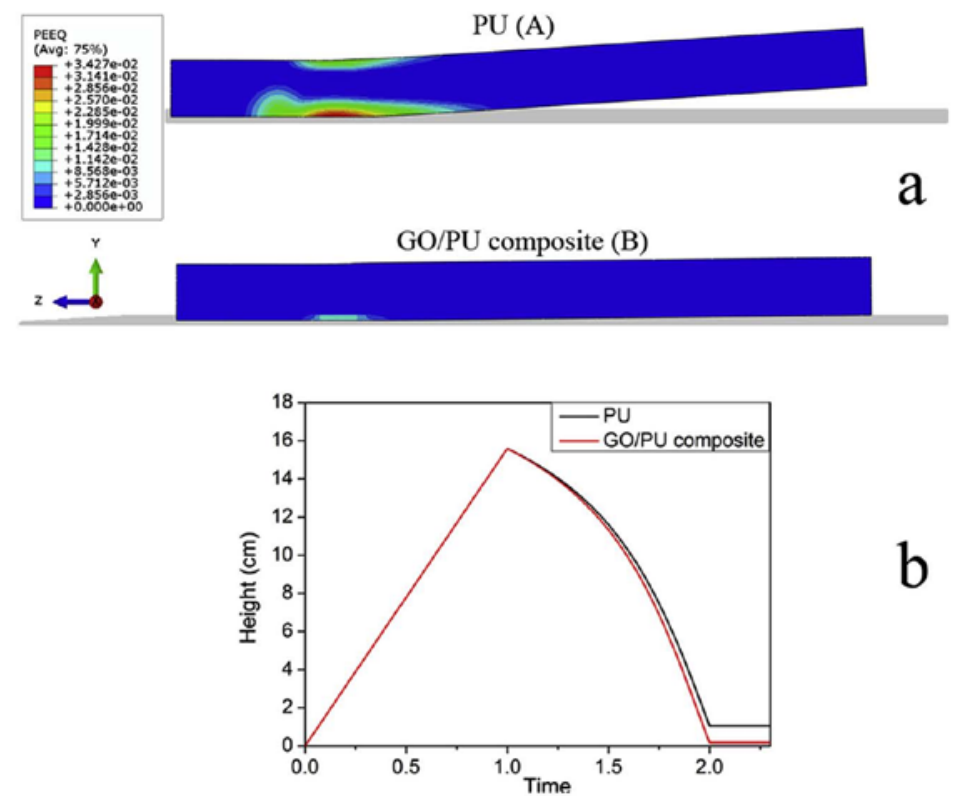

$\mathrm{b}$

Fig. 8. (a) Contours of equivalent plastic strain (PEEQ) of side surfaces for PU (A) and GO/PU composite (B) (b) Height-time curves for PU and GO/PU composite.

Table 1

Areas measured based on PEEQ contour.

\begin{tabular}{|c|c|c|c|c|}
\hline & Initial total area (pixels) & Total area after unloading (pixels) & Plastic area (pixels) & Plastic area fraction (\%) \\
\hline \multicolumn{5}{|l|}{$\overline{\text { PU }}$} \\
\hline Side surface & 165,200 & 187,312 & 28,197 & 15.1 \\
\hline Top surface & 181,830 & 175,802 & 44,806 & 25.5 \\
\hline Side surface & 165,200 & 188,072 & 2227 & 1.2 \\
\hline Top surface & 181,830 & 180,345 & 2167 & 1.2 \\
\hline Bottom surface & 181,830 & 180,678 & 12,630 & 7.0 \\
\hline
\end{tabular}

Table 2

Residual height and final specific plastic dissipation energy of three specimens for each material: PU and GO/PU composite.

\begin{tabular}{lll}
\hline & $\begin{array}{l}\text { Residual } \\
\text { height }(\mathrm{cm})\end{array}$ & $\begin{array}{l}\text { Final specific plastic } \\
\text { dissipation energy }\left(\mathrm{J} / \mathrm{cm}^{3}\right)\end{array}$ \\
\hline PU-1 & 1.08 & $4.99 \mathrm{E}-03$ \\
PU-2 & 1.24 & $6.17 \mathrm{E}-03$ \\
PU-3 & 0.89 & $4.37 \mathrm{E}-03$ \\
Average & 1.07 & $5.17 \mathrm{E}-03$ \\
GO/PU-1 & 0.20 & $3.13 \mathrm{E}-04$ \\
GO/PU-2 & 0.18 & $2.73 \mathrm{E}-04$ \\
GO/PU-3 & 0.20 & $2.92 \mathrm{E}-04$ \\
Average & 0.19 & $2.92 \mathrm{E}-04$ \\
\hline
\end{tabular}

\subsection{Specific plastic dissipation energy}

Numerical simulations allow calculating other important mechanical features that can be hardly obtained in experimental tests: Fig. 10 show evolution of specific plastic dissipation energy in PU and the GO/PU composite in a loading-unloading cycle. At the initial stage of loading, there was no plastic dissipation of energy, indicating that this stage was completely elastic. Then, plastic dissipation energy started to arise and reached its peak at highest deflection.
Finally, during the unloading process, the specific plastic dissipation energy kept constant till the end of this process, since there was no further plastic deformation induced. Compared with PU, the $\mathrm{GO} / \mathrm{PU}$ composite exhibited a significantly lower value of the final specific plastic dissipation energy (detailed information is in Table 2) More importantly, the point, from which the curve started to climb, revealed the point of bending process corresponding to the onset of plastic deformation. Observed from the data, the PU started to yield at a height of $8.73 \mathrm{~cm}$, while that process was delayed to a height of $13.56 \mathrm{~cm}$ for the GO/PU composite. This information is very helpful for the design of shoe soles allowing to reduce plastic deformation, or even to avoid it completely.

Three specimens of the two studied material were analysed in the experimental cyclic tensile tests, as well as in the subsequent finite-element simulations based on the stress-strain curves obtained for each specimen. The values of residual height and final specific plastic dissipation energy are listed in Table 2 together with their averages. As can be seen, the average residual height for the PU model was $1.07 \mathrm{~cm}$, approximately 5.6 times as large as that for the model of the GO/PU composite. The average final specific plastic dissipation energy for PU was $5.17 \mathrm{E}-03 \mathrm{~J} / \mathrm{cm}^{3}$, almost 17.7 times as large as that for the studied composite. 

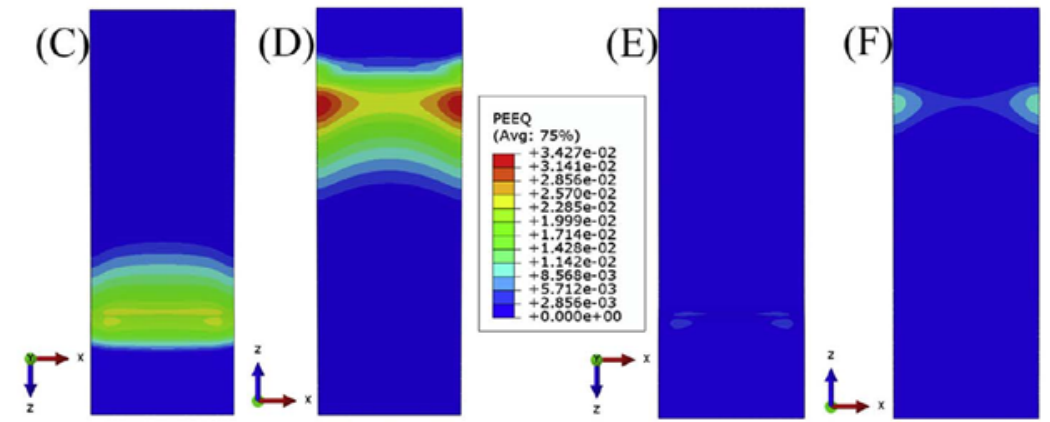

Fig. 9. Contours of equivalent plastic strain (PEEQ) of top surfaces (C, E) and bottom surfaces (D, F) for PU (C, D) and GO/PU composite (E, F).

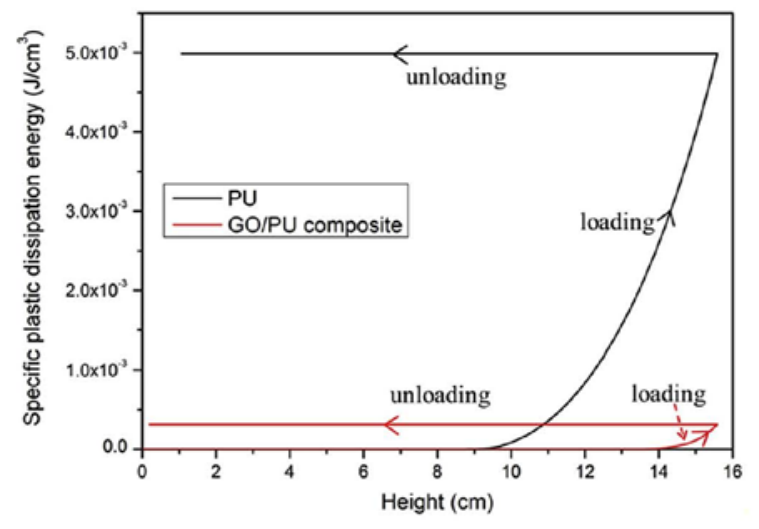

Fig. 10. Evolution of specific plastic dissipation energy with deflection (height) for PU and $\mathrm{GO} / \mathrm{PU}$ composite.

\section{Conclusions}

Go, containing massive functional oxygen groups on its surfaces and edges, was used as the nanofiller to prepare a GO/PU composite. Based on the experimental cyclic tensile tests, the level of plastic strains for both PU and the GO/PU composite became nearly stable after 50 loading-unloading cycles, and the extent of plasticity of PU was demonstrated to be reduced with the addition of GO. Additionally, in order to study the mechanical performance of PU and the GO/PU composite under conditions of large-deflection bending deformation, typical for shoe soles, the finite-element analysis was conducted with Abaqus/Standard. An elastic-plastic finite-element model was developed to obtain the detailed mechanical information for pure PU and the nanocomposite. Both experiment and simulation results of the uniaxial tensile tests were highly consistent, thus verifying the accuracy of the constructed model.

From the performed numerical simulations of the largedeflection bending for both materials, it was found that the von Mises stress was mostly concentrated at the bending part of the model, and the GO/PU composite exhibited higher von Mises stress overall compared with that in PU. More importantly, the plastic area, final specific plastic dissipation energy and residual height for PU were significantly larger than those of the GO/PU composite. Besides, the addition of $\mathrm{GO}$ into the PU matrix greatly delayed the onset of plastic deformation in PU in the large-deflection bending process. Simulations of three specimens of each material based on experimentally obtained stress-strain data, demonstrated that the average residual height for PU was $1.07 \mathrm{~cm}$, i.e. approximately 5.6 times as large as that for the $\mathrm{GO} / \mathrm{PU}$ composite. The average final specific plastic dissipation energy for PU was $5.17 \mathrm{E}-03 \mathrm{~J} / \mathrm{cm}^{3}$, almost 17.7 times as large as that for the GO/PU composite. The detailed mechanical information from the finite-element analysis quantitatively revealed the enhancing effect of $\mathrm{GO}$ on the large-deflection bending performance of PU and can be used for design and optimisation of shoe soles of real products.

\section{Acknowledgements}

The financial support from the Institute for Sports Research, Nanyang Technological University (NTU), Singapore is appreciated. The FESEM and TEM work was performed at the Facility for Analysis, Characterization, Testing and Simulation (FACTS) of NTU.

\section{References}

11 Geim AK. Graphene: status and prospects. Science 2009;324(5934):1530-4.

[2] Park S, Ruoff RS. Chemical methods for the production of graphenes (vol. 4, ps 217, 2009). Nat Nanotechnol 2010;5(4):309

[3] Lee C, Wei X, Kysar JW, Hone J. Measurement of the elastic properties and intrinsic strength of monolayer graphene. Science 2008:321(5887):385-8.

[4] Eswaraiah V, Balasubramaniam K, Ramaprabhu S. One-pot synthesis of conducting graphene-polymer composites and their strain sensing application Nanoscale 2012;4(4):1258-62.

[5] Zhou T, Zhou XM, Xing D. Controlled release of doxorubicin from graphene oxide based charge-reversal nanocarrier. Biomaterials 2014;35(13):4185-94,

[6] Pan YZ, Bao HQ Sahoo NG, Wu TF, Li L. Water-soluble poly(nisopropylacrylamide)-graphene sheets synthesized via click chemistry for drug delivery. Adv Funct Mater 2011;21(14):2754-63.

[7] Mensing JP, Wisitsoraat A, Phokharatkul D, Lomas T, Tuantranont A. Nove surfactant-stabilized graphene-polyaniline composite nanofiber for supercapacitor applications. Compos Part B Eng 2015;77(0):93-9.

[8] Sen I, Seki Y, Sarikanat M, Cetin L, Gurses BO, Ozdemir O, et al. Electroactive behavior of graphene nanoplatelets loaded cellulose composite actuators. Compos Part B Eng 2015;69(0):369-77.

[9] Joshi A, Bajaj A, Singh R, Anand A, Alegaonkar PS, Datar S. Processing of graphene nanoribbon based hybrid composite for electromagnetic shielding. Compos Part B Eng 2015;69(0):472-7.

[10] Lu H, Yao Y, Huang WM, Hui D. Noncovalently functionalized carbon fiber by grafted self-assembled graphene oxide and the synergistic effect on polymeric grafted self-assembled graphene oxide and the synergistic effect on polym
shape memory nanocomposites. Compos Part B Eng 2014;67(0):290-5.

[11] Park S, Ruoff RS. Chemical methods for the production of graphenes. Nat Nanotechnol 2009:4(4):217-24.

[12] Sebenik U, Krajnc M. Influence of the soft segment length and content on the synthesis and properties of isocyanate-terminated urethane prepolymers. In J Adhesion Adhesives 2007;27(7):527-35

[13] Ames KA. Elastomers for shoe applications. Rubber Chem Technol 2004;77(3): 413-75.

[14] Camargo RE, Roberts CM, Limerkens $N$. Thermoplastic polyurethanes: new material options for high performance footwear. In: Polyurethanes conference 2000: proceedings of the polyurethanes conference 2000: October 8-11, 2000. Boston, Massachusetts: American Plastics Council; 2000. p. 49. 
[15] Inc CC In: UTECH Asia '99: conference book of papers: the international polyurethanes conference \& exhibition for Asia-Pacific: March 16-18, 1999. Suntec City, Singapore: Crain Communications: 1999

[16] Salm W. Almost like flying. Kunstst Eur 1999;89(7):118-20.

[17] Buckley CP, Prisacariu C, Martin C. Elasticity and inelasticity of thermoplastic polyurethane elastomers: sensitivity to chemical and physical structure Polymer 2010;51(14):3213-24

[18] Prisacariu C Polyurethane elastomers: from morphology to mechanical as pects. Springer Science \& Business Media; 2011.

[19] Christenson EM, Anderson JM, Hiltner A, Baer E. Relationship between nanoscale deformation processes and elastic behavior of polyurethane elastomers, Polymer 2005:46(25):1744-54,

[20] Cho JW, Kim JW, Jung YC, Goo NS. Electroactive shape-memory polyurethane composites incorporating carbon nanotubes. Macromol Rapid Comm 2005;26(5):412-6.

[21] Lerf A, He H. Forster M, Klinowski J. Structure of graphite oxide revisited. J Phys Chem B 1998;102(23):4477-82.

[22] Hontoria-Lucas C. López-Peinado AJ, López-González JdD, Rojas-Cervantes ML Martín-Aranda RM. Study of oxygen-containing groups in a series of graphite oxides: physical and chemical characterization. Carbon 1995:33(11) $1585-92$

[23] Stankovich S, Piner RD, Nguyen ST, Ruoff RS. Synthesis and exfoliation of isocyanate-treated graphene oxide nanoplatelets. Carbon 2006;44(15): $3342-7$.

[24] Erickson K, Erni R, Lee Z, Alem N, Gannett W, Zettl A. Determination of the local chemical structure of graphene oxide and reduced graphene oxide. Adv Mater 2010:22(40):4467-72
[25] Wu C, Huang X, Wang G, Wu X, Yang K, Li S, et al. Hyperbranched-polymer functionalization of graphene sheets for enhanced mechanical and dielectric functionalization of graphene sheets for enhanced mechanical and dielectric

[26] Zheng Q. Ip WH, Lin X, Yousefi N, Yeung KK, Li Z, et al. Transparent conductive films consisting of ultralarge graphene sheets produced by langmuirfilms consisting of ultralarge graphene sheets
Blodgett assembly. ACS Nano 2011;5(7):6039-51.

[27] Park J, Kim B. Infrared light actuated shape memory effects in crystalline poly(1)

[28] Choi JT, Dao TD, Oh KM, Lee H-1, Jeong HM, Kim BK. Shape memory polyurethane nanocomposites with functionalized graphene. Smart Mater Struct 2012;21(7), 075017.

[29] Deka H, Karak N, Kalita RD, Buragohain AK. Biocompatible hyperbranched polyurethane/multi-walled carbon nanotube composites as shape memory materials. Carbon 2010;48(7):2013-22.

[30] Han S, Chun BC Preparation of polyurethane nanocomposites via covalent incorporation of functionalized graphene and its shape memory effect Compos Part A Appl Sci Manuf 2014;58:65-72.

[31] Prisacariu C, Scortanu E. Sensitivity to the physical and chemical structure of hard-segment-reinforced polyurethane elastomers with variable percentage of hydrogen bonding. J Appl Polym Sci 2011:122(6):3544-50.

[32] Park J Dao T. Lee H-L Jeong H, Kim B. Properties of graphene/shape memory thermoplastic polyurethane composites actuating by various methods. Materials 2014;7(3):1520-38.

[33] Bonet 1, Wood RD. Nonlinear continuum mechanics for finite element analysis. Cambridge University Press; 1997.

[34] Shabana A. Computational continuum mechanics. New York: Cambridge: University Press; 2008. 